rouleaux and making it very difficult, or impossible, to read the result. Clotting can usually be completed within a few seconds by adding a drop of thrombin solution or a fragment of solid thrombin. Thrombin is sold commercially and should be available in all hospital laboratories.

It must be very unusual to have to give blood so quickly that one cannot wait for the blood to clot; the only such occasion the writer can remember was with a bleeding haemophiliac, but his blood was clotted quickly with thrombin. In nearly all desperate emergencies infusion of plasma or dextran will maintain blood volume and blood pressure for long enough to permit cross-matching by one of the rapid methods (for example, by the tube-centrifuge method) ; and, if this takes too long, one may have to use un-crossmatched blood of Group 0 , preferably Rhesus negative. This should be a very rare necessity-perhaps once in several thousand transfusions.

\section{Treatment of Progressive Exophthalmos}

Q. -What treatment is advised in cases of exophthalmic goitre where the condition is well controlled by propyl thiouracil but the patient is developing severe exophthalmos?

A.-Exophthalmos may develop or become more marked in patients with Graves's disease whether treated by antithyroid drugs, radio-iodine, or partial thyroidectomy. It has been suggested that, as treatment reduces the plasma level of thyroid hormone, the pituitary secretes increased amounts of thyrotrophin (which causes enlargement of the thyroid gland) and of the hypothetical exophthalmos-producingsubstance (which increases the proptosis). In an attempt to suppress pituitary overactivity thyroid extract, 2-3 gr. $(0.13-0.2 \mathrm{~g}$.), or thyroxine, $0.2-0.3 \mathrm{mg}$., may be given daily concurrently with antithyroid treatment ; this usually prevents further thyroid enlargement and may arrest further progression of the exophthalmos.

If the exophthalmos increases despite this treatment, a variety of other measures may be tried, their large number indicating that none is invariably effective-bed rest, heavy sedation, cortisone, $x$-ray therapy to the pituitary or orbital tissues, or, in severe cases when sight is threatened, decompression of the orbit by the temporal route. The eye symptoms are usually self-limiting. and after a variable time the exophthalmos stops progressing and may even recede a little, but the cosmetic result is seldom good.

\section{Taste and Odour of Milk}

Q.-What substances in milks of different origin-human. cow, goat, etc.-account for their different tastes and odours?

A.- The differences in the tastes of the milks of different species, provided the milk has been produced under clean conditions by healthy animals and kept under cool conditions, are due to the variations in the actual and relative proportions of lactose, various salts, fat, proteins, etc., present, and to differences in $p \mathrm{H}$. The constitution of the fat, and the fat globule size, may also play a part, but the lactose and salts have the greatest influence. For example, human milk has a much higher lactose content, and a lower sodium chloride content, than cow's milk, and it is higher in $p \mathrm{H}$.

Odours are seldom detectable in really clean, fresh milk, although under poor conditions odours are readily picked up from the animal and its surroundings. But if the milk is kept under conditions which favour even slight bacterial or enzymic breakdown of its constituents, then odoursdifferent odours-arise from the varying types and proportions of volatile acids, etc., resulting mainly from the decomposition of the fats and lactose. The milk fats of the different species differ markedly in the proportions of combined fatty acids present, and this affects the odour; for example, goat's milk fat contains an unusually high proportion of capric acid $\left(\mathrm{C}_{9} \mathrm{H}_{19} \mathrm{COOH}\right)$-hence the acid's name-which has a characteristic "goaty" odour in the free form in which small amounts are liberated by the action of lipase.

\section{Alcohol in Peptic Ulcer}

Q.-Is it still regarded as necessary to ban alcohol completely in peptic ulcer, or are drinks of low alcoholic content, such as beer, harmless in moderate quantities for such cases? What about wines?

A.-There is no convincing scientific evidence that alcohol is harmful to patients with peptic ulcer. There is, however, a strong impression that certain types of alcohol are worse than others, and it is known that alcohol is a strong stimulant of gastric secretion. It is probably wise to forbid alcohol altogether during the stage of active treatment of an ulcer, and this ban should possibly be maintained for as long as three months. After that time there would seem no reason not to allow beer, diluted spirits, or wine, so long as the quantity taken is moderate and they are not taken on an empty stomach. There is a strong impression that brandy is particularly liable to bring on pain and that red wine is worse than white wine. In both cases the effect may be due to the presence of irritant substances other than alcohol.

\section{Massage for Unwelcome Contours}

Q.-Can massage disperse local accumulations of fat? If so, where do they go?

A.-Fat, being semi-fluid at body temperature, can be "shifted about" to some extent by a skilled masseuse or with a vibrator. But massage, while being possibly able slightly to alter contours. will not reduce weight. There is no éasy short cut to loss of weight or girth in massage.

\section{Metallic Taste in Mouth}

Q.-What are the possible causes of an unpleasant metallic taste in the mouth, and how may it be prevented?

A.-An unpleasant metallic taste in the mouth is occasionally caused by galvanic action taking place between two dissimilar metals - for example, when gold dentures are in intermittent contact with amalgam fillings. In the majority of cases there is, however, no local cause for this symptom, which must be regarded as functional. It is rather common in women over 50 years of age.

Correction.-In the list of "Approved Names" printed in our issue of October 26 (p. 995), hydroxydione sodium succinate should have been described as an intravenous basal anaesthetic.

Collected Articles from the "British Medical Journal "

The following books are available through booksellers or from the Publishing Manager, B.M.A. House. Prices, which include postage, are now the same for both inland and overseas.

Emergencies in General Practice (26s. 9d.).

Refresher Course for General Practitioners, Volumes 2 and 3 (26s. 9d. each).

Clinical Pathology in General Practice (22s. 3d.).

Any Questions?, Volumes 2 and 3 (8s. 3d. each).

All communications with regard to editorial business should be addressed to THE EDITOR, BRITISH MEDICAL JOURNAL B M A. HOUSE, TAVISTOCK SOUARE, LONDON W.C.1. TELFPHONF: EUSTON 4499 TFLFGRAMS Aitiology, Westcent, London. ORIGINAL ARTICLES AND LETTERS forwarded for publication are understood to be offered to the British Medical Journal alone unless the contrary be stated.

Authors desıring REPRINTS should communicate with the Publishing Manager. B.M.A. House, Tavistock Square, W.C.1, on receipt of proofs. Authors overseas should indicate on MSS. if reprints are required, as proofs are not sent abroad.

ADVERTISEMENTS should be addressed to the Advertisement Director B.M.A. House, Tavistock Square, London, W.C.1 (hours 9 a.m. to 5 p.m.). TELEPHONE: EUSTON 4499. TeleGrams: Britmedads.

Westcent, London.
MEMBERS' SUBSCRIPTIONS should be sent to the SECRETARY of the Association. TElePHONE: EUSTON 4499. TELEGAMS: Medisecra, Westcent, London.

B.M.A. SCOTtish OFfice: 7, Drumsheugh Gardens, Edinburgh. 